\title{
Locally Advanced or Metastatic Pancreatic Adenocarcinoma: Easily Available Factors of Predictive Prolonged Survival Under Gemcitabine
}

\author{
ANNE PLOQUIN $^{1}$, STEPHANIE TRUANT ${ }^{2}$, GUILLAUME PIESSEN ${ }^{3}$, PERRINE VUAGNAT $^{1}$, \\ CAPUCINE BALDINI $^{1}$, STEPHANE CATTAN ${ }^{4}$ and MOHAMED HEBBAR ${ }^{1}$ \\ Departments of ${ }^{1}$ Medical Oncology, ${ }^{2}$ Digestive Surgery and Transplantation, \\ ${ }^{3}$ Digestive and Oncological Surgery, ${ }^{4}$ Hepatogastroenterology, University Hospital, Lille, France
}

\begin{abstract}
Background: Prognosis of patients with locally advanced or metastatic pancreatic adenocarcinoma is poor. In this study, we assessed the predictive value of easily available baseline factors for prolonged survival. Patients and Methods: We conducted a retrospective study on patients who received gemcitabine between 1999 and 2010 for locally advanced or metastatic pancreatic adenocarcinoma. The primary end-point was the 12-month survival rate. Results: We included 195 patients. The median age was 62.9 years; the performance status was $0-1$ in 80 and 2-3 in 92 patients. The median number of metastatic sites was one. A total of 73 patients (37.4\%) were alive 12 months after beginning chemotherapy. In multivariate analysis, no liver metastasis, CA19-9 level $<250 \mathrm{IU} / \mathrm{ml}$ and localized or locally advanced cancer at diagnosis were good prognostic factors. According to a clinical score based on these features, overall survival was 7.7, 13.5, 19.7 and 21.0 months, respectively $(p<0.001)$. Conclusion: We identified easily available prognostic factors for prolonged survival in patients treated with gemcitabine.
\end{abstract}

Pancreatic adenocarcinoma (PA) is the fourth cause of cancer-related deaths (1). Surgical resection represents the only hope for cure but only $10-20 \%$ of patients present with a surgically-resectable tumour.

For advanced and metastatic PA, systemic chemotherapy with single-agent nucleoside analogue gemcitabine is currently recommended as a standard in first-line treatment,

This article is freely accessible online.

Correspondence to: Dr Anne Ploquin, Service d'Oncologie Médicale, Centre Hospitalo-Universitaire, 1 rue Michel Polonovski, 59037 Lille, France. Tel: +33 320445461, Fax: +33 320445023, e-mail: anne.ploquin@chru-lille.fr

Key Words: Pancreas, prognostic factor, liver metastasis, CA19-9. with a significantly improved quality of life, and a median overall survival (OS) of 6-9 months (2). Although the absolute survival benefit remains poor and controversial, some patients (18\%) survive more than 12 months (2). Gemcitabine chemotherapy has represented the single standard therapy for PA for more than a decade. Recently, a randomized trial compared gemcitabine and 5fluorouracil/leucovorin/irinotecan/oxaliplatin combination (FOLFIRINOX) in front-line treatment of 342 patients with locally advanced or metastatic PA (3). The FOLFIRINOX regimen was superior to gemcitabine in terms of OS (11.1 vs. 6.8 months), progression-free survival (PFS) (6.4 vs. 3.3 months), and objective response rate (31.6 vs. 9.4\%). Moreover, a recent update indicated that FOLFIRINOX was also superior in terms of quality of life (4). FOLFIRINOX is now the standard therapy in FRANCE. Yet FOLFIRINOX use is restricted to selected patients with preserved Eastern Cooperative Oncology Group performance status of $0-1$, and with normal bilirubinemia. The toxicity of FOLFIRINOX is significant, especially in regard to the cumulative oxaliplatinrelated neurotoxicity. To avoid this toxicity, it would be useful to have easily available factors predictive of long survival with gemcitabine alone. The aim of the present study was to assess these potent predictive factors.

\section{Patients and Methods}

Patients. We conducted a multicentric retrospective study between 1999 and 2010 at two centres in northern France before the advent of FOLFIRINOX (3). Inclusion criteria were: age >18 years; an histologically confirmed PA or a tumour radiologically suggestive of PA growing between two different computed tomographic (CT) scans or magnetic resonance imaging (MRI); locally advanced or metastatic tumor, and no previous chemotherapy.

Gemcitabine was administered at $1,000 \mathrm{mg} / \mathrm{m}^{2}$ intravenously over 30 minutes weekly for 7 weeks followed by a 1-week break. Subsequent cycles consisted of weekly administrations 3 weeks out of 4. Radiological evaluations by CT scan or MRI were repeated every 2 months. Gemcitabine was stopped if the patient presented 
a limiting toxicity or a tumoural progression according to response evaluation criteria in solid tumor (RECIST) (5).

We assessed the prognostic value of the following features: demographical: age, gender; clinical: performance status, jaundice at diagnosis; tumoural: histology, intrapancreatic localisation, initial stage, differentiation, number of metastatic sites, metastasis localisation; and carcinona antigen 19-9 (CA19-9) concentration. The primary end-point was 12-month OS.

Statistical analyses. OS was calculated from diagnosis of metastatic or locally advanced disease to death.

Univariate analysis was conducted on all variables with chisquare test. The continuous variables expressed as median (range) were tested as they were and then were separated into groups based on deciles. The prognostic factors significant at a level of 0.20 were included in a multivariate analysis conducted with logistic regression.

We then created a score based on prognostic factors, with one point given to each factor, and the statistical significance of this score was tested with chi-square test on 12-month OS rate and with Cox model on OS.

\section{Results}

Patients. The study was performed on 195 consecutive patients. The median age was 62.9 years (range 28.6-84.4). The sex ratio $(\mathrm{M} / \mathrm{F})$ was $100 / 95$. Eighty patients $(41.0 \%)$ had an ECOG status of $0-1$, and $92(47.2 \%)$ of 2-3. The disease was revealed by jaundice in $72(36.9 \%)$ patients. Tumour location was in the pancreatic head in the mistily of cases [127 $(65.1 \%)]$. Adenocarcinoma was histologically confirmed in 154 cases $(79.0 \%)$, and well-differentiated in 30 patients $(15.4 \%)$. At diagnosis, only 33 patients $(17.0 \%)$ had a localized tumor. At inclusion, the median number of metastatic sites was one, involving mainly the liver in 116 patients $(59.5 \%)$ or the peritoneum in 45 patients $(23.1 \%)$. The median CA19-9 concentration was 636 (range $=1-372,000) \mathrm{IU} / \mathrm{ml}$ (Table I).

A total of 51 patients $(26.1 \%)$ received second-line chemotherapy of capecitabine, leucovorin and fluorouracil (LV5FU2)-cisplatin, tomudex and oxalipatine (TOMOX), gemcitabine and oxaliplatine (GEMOX), 5FU, irinotecan and oxaliplatine (FOLFIRINOX) or tomudex. Among the 57 patients with locally advanced cancer, four had surgery, two after chemotherapy, one after radiotherapy and one after radiochemotherapy; 11 patients received radiochemotherapy without surgery.

The median overall survival was 10.1 (0.8-116.3) months, with 73 patients $(37.4 \%)$ alive 12 months after diagnosis.

Factors predictive of prolonged survival $>12$ months. Among the 16 assessed variables, eight were identified as having a good prognostic value on univariate analysis: jaundice $(p=0.005)$, locally advanced tumour at inclusion $(p=0.030)$, no synchronous metastasis at diagnosis $(p<0.001)$, bone metastasis $(p=0.133)$, no liver metastasis at diagnosis
Table I. Characteristics of patients at baseline.

\begin{tabular}{|c|c|c|c|}
\hline Characteristic & $\begin{array}{c}\text { Median } \\
(\min -\max )\end{array}$ & $\begin{array}{c}\text { Number } \\
(\%)\end{array}$ & $\begin{array}{c}\text { Missing } \\
\text { values }\end{array}$ \\
\hline Age, years & $62.9(28.6-84.4)$ & & 0 \\
\hline Male gender & & $100(53.5 \%)$ & 0 \\
\hline Performance status & & & $23(11.8 \%)$ \\
\hline 0 & & $16(9.3 \%)$ & \\
\hline 1 & & $64(37.2 \%)$ & \\
\hline 2 & & $66(38.4 \%)$ & \\
\hline 3 & & $26(15.1 \%)$ & \\
\hline Jaundice at diagnosis & & $72(39.6 \%)$ & $13(6.7 \%)$ \\
\hline CA19-9 (IU/ml) & $636.3(1-372000)$ & & $53(27.2 \%)$ \\
\hline $\begin{array}{l}\text { Elevated CA19-9 } \\
(>5 \mathrm{IU} / \mathrm{ml})\end{array}$ & & $115(76.2 \%)$ & $44(22.6 \%)$ \\
\hline Tumour location & & & $12(6.2 \%)$ \\
\hline Head & & $127(69.8 \%)$ & \\
\hline Body & & $29(15.9 \%)$ & \\
\hline Tail & & $26(14.3 \%)$ & \\
\hline Histological proof & & $154(79.0 \%)$ & 0 \\
\hline Differentiation & & & $101(51.8 \%)$ \\
\hline Well & & $30(31.9 \%)$ & \\
\hline Moderate & & $55(58.5 \%)$ & \\
\hline Poor & & $7(7.4 \%)$ & \\
\hline Locally advanced disease & & $57(29.2 \%)$ & 0 \\
\hline Metastatic disease & & $105(54.1 \%)$ & \\
\hline Number of metastatic sites & $1(0-3)$ & & $8(4.1 \%)$ \\
\hline Liver metastasis & & $116(59.5 \%)$ & 0 \\
\hline Lung metastasis & & $18(9.2 \%)$ & 0 \\
\hline Peritoneal carcinomatosis & & $45(23.1 \%)$ & 0 \\
\hline Bone metastases & & $6(3.1 \%)$ & 0 \\
\hline
\end{tabular}

CA19-9: Cancer antigen 19-9.

$(p<0.001)$, CA19-9 $<250 \mathrm{IU} / \mathrm{ml}(p=0.013)$, histological proof $(p=0.052)$, and head location $(p=0.149)$ (Table II).

Among the eight variables included in multivariate analysis, three were identified as having good prognostic value: no liver metastasis at diagnosis $(p=0.001)$, CA19-9 $<250 \mathrm{IU} / \mathrm{ml}(p=0.009)$ and no synchronous metastasis at diagnosis $(p=0.015)$ (Table III).

We then created a clinical score ascribing one point for each good prognostic feature. This score of 0 to 3 points was tested for correlation to 12 -month OS $(p<0.001)$ in chisquare test.

The OS according to clinical scores of $0,1,2$ and 3 was $7.7,13.5,19.7$ and 21.0 months, respectively $(p<0.001)$ (Figure 1). Two-thirds of patients with 3 points had an OS $>12$ months.

\section{Discussion}

In this study on 195 patients with PA treated with gemcitabine alone, we constructed a prognostic score form easily available clinical and biological features. We showed 
Table II. Univariate analysis of 12 months overall survival (OS) with chi-square test.

\begin{tabular}{lcc}
\hline Factor & $\begin{array}{c}\text { OS }>12 \text { months } \\
(\mathrm{N}=73,37.4 \%), \mathrm{n}(\%)\end{array}$ & $p$-Value \\
\hline Male & $43(38.4 \%)$ & 0.595 \\
Jaundice & $35(48.6 \%)$ & 0.005 \\
PS 0-1 & $35(39.8 \%)$ & 0.726 \\
Locally advanced disease & $28(49.1 \%)$ & 0.030 \\
No synchronous metastasis & $24(22.8 \%)$ & $<0.001$ \\
1 or 2 metastases & $58(34.5 \%)$ & 0.345 \\
No liver metastasis & $31(26.7 \%)$ & $<0.001$ \\
Bone metastasis & $4(66.7 \%)$ & 0.133 \\
Lung metastasis & $8(44.4 \%)$ & 0.519 \\
Peritoneal carcinomatosis & $14(31.1 \%)$ & 0.318 \\
Histological proof & $63(40.9 \%)$ & 0.052 \\
Well-differentiated & $16(51.6 \%)$ & 0.258 \\
Location & & 0.149 \\
$\quad$ Head & $53(41.7 \%)$ & \\
$\quad$ Body & $7(24.1 \%)$ & \\
$\quad$ Tail & $8(30.8 \%)$ & \\
Age $>62.9$ years & $37(35.2 \%)$ & 0.546 \\
CA19-9 <250 IUl/ml & $50(32.2 \%)$ & 0.013 \\
\hline
\end{tabular}

PS: Performance status; CA19-9: cancer antigen 19-9.

Table III. Multivariate analysis of odds of overall survival.

\begin{tabular}{lcc}
\hline Factor & OR $(95 \% \mathrm{CI})$ & $p$-Value \\
\hline No liver metastasis & $3.8(1.7-8.6)$ & 0.001 \\
CA19-9 <250 IU/ml & $2.9(1.3-6.6)$ & 0.009 \\
No synchronous metastasis & $2.7(1.2-5.9)$ & 0.015 \\
Bone metastasis & $0.2(0.02-1.3)$ & 0.083 \\
Head location & $0.4(0.1-1.3)$ & 0.225 \\
Locally advanced & $0.7(0.3-2.2)$ & 0.605 \\
Jaundice & $0.6(0.3-1.3)$ & 0.195 \\
Histoloical proof & $0.6(0.2-2.0)$ & 0.414 \\
\hline
\end{tabular}

OR: Odds ratio; CA19-9: cancer antigen 19-9; CI: confidence interval.

that the absence of liver metastases, a CA19-9 concentration $<250 \mathrm{IU} / \mathrm{ml}$ and the absence of synchronous metastasis at diagnosis were significantly associated with a prolonged OS (>12 months), with median OS of 21.0 months for patients with all three good prognosis factors.

The presence of synchronous metastases is an expected poor prognostic factor in several cancer types including of the pancreas (6-10). Liver metastasis is a known poor prognostic factor, and CA19-9 is described as poor prognostic factor in different studies, without a clear cut-off $(6,11,12)$. Here we found that CA19-9 was a factor of poor prognosis when exceeding $250 \mathrm{IU} / \mathrm{ml}$. In our study, the

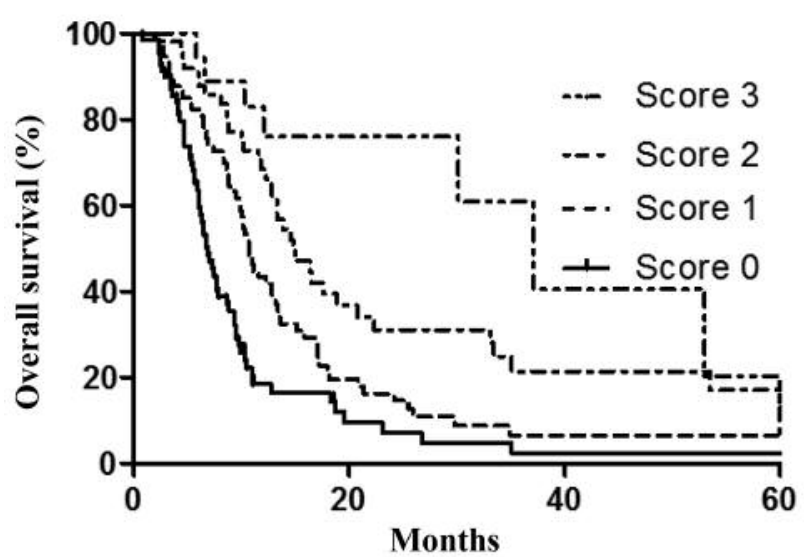

\begin{tabular}{|c|c|c|c|c|c|c|c|}
\hline No at risk & \multicolumn{7}{|c|}{ Time (months) } \\
\hline & 0 & 10 & 20 & 30 & 40 & 50 & 60 \\
\hline Score 0 & 69 & 16 & 4 & 2 & 1 & 1 & 1 \\
\hline Score 1 & 76 & 43 & 12 & 4 & 3 & 3 & 3 \\
\hline Score 2 & 50 & 36 & 14 & 10 & 6 & 6 & 4 \\
\hline Score 3 & 18 & 15 & 5 & 5 & 2 & 2 & 1 \\
\hline
\end{tabular}

Figure 1. Overall survival according to the clinical score: 0, 1, 2 or 3 good prognostic factors between: no liver metastasis, CA 19-9 <250 and localized or locally advanced pancreatic cancer at diagnostic.

performance status (a subjective value) was not included, which means that all the relevant features used for our scorer here are objective. Our score is easily applicable in routine practice.

A limitation of this study is its retrospective nature. Moreover, we had much missing data, especially regarding CA19-9 concentration (22.6\%). Our score needs to be confirmed in an independent cohort or by a prospective study.

In a recent study, a neutrophil/lymphocyte ratio of 2 or more was a prognostic factor for resectable pancreatic cancer (13). In another study, the lymphocyte/monocyte ratio was a good prognostic factor (13). Recently, several studies focused on the tumoural expression of the nucleoside transporter human equilibrative nucleoside transporter (hENT1) $(10,11,14,15)$. A high expression of hENT1 seems to be associated with a greater efficacy of gemcitabine. Yet the prognostic value of this remains controversial and has been mainly assessed in an adjuvant setting (16-18). The prognostic value of this expression seems to vary according to the antibody used. In a recent study, Svrcek et al. showed that murine antibody to hENT1 was predictive of OS in patients treated by gemcitabine, but rabbit antibody was not (19). Moreover, hENT1 expression is not currently routinely assessed. 
Furthermore, recent studies showed several biomarkers in immunohistochemistry (20) or with polymerase chain reaction (PCR) analysis (21). However, such methods are not easily feasible in clinical practice.

The prognostic factors defined in the present study can be useful in selecting long surviving patients who will benefit more from gemcitabine and who can be spared from FOLFIRINOX toxicity. Indeed, FOLFIRINOX regimen is associated with several severe toxicities (grade 3-4) with $45.7 \%$ experiencing neutropenia, $23.6 \%$ fatigue, $14.5 \%$ vomiting, and $12.7 \%$ diarrhea in the study of Conroy et al. (3). Recently, new combination with gemcitabine and nabpaclitaxel led to longer OS than gemcitabine alone, with acceptable toxicities such as neuropathy (22). However, nabpaclitaxel is not available in many countries, such as France.

Nowadays, the aim of the clinician is to choose the best strategy to obtain long survival with acceptable toxicity. In long surving patients, starting with a less toxic chemotherapy, such as gemcitabine, and switching to FOLFIRINOX at progression could be an effective strategy to achieve greater survival without toxicity.

Two studies are recruiting to test such different strategies. PRODIGE 35 aims to compare a standard 12 cycles of FOLFIRINOX followed by monitoring versus eight cycles of FOLFIRINOX followed by LV5FU2 versus alternate FOLFIRI for 2 months and gemcitabine for 2 months. PRODIGE 37 is evaluating another standard of gemcitabine plus nab-paclitaxel versus alternate FOLFIRI for 2 months and gemcitabine plus nab-paclitaxel for 2 months.

To conclude, the results of the present study suggest that using easily available prognostic factors could define patients who would have prolonged survival with gemcitabine alone, and whom could be spared from the higher toxicity of more aggressive regimens.

\section{References}

1 Jemal A, Siegel R, Xu J and Ward E: Cancer statistics. CA Cancer J Clin 60: 277-300, 2010.

2 Burris HA 3rd, Moore MJ, Andersen J, Green MR, Rothenberg ML, Modiano MR, Cripps MC, Portenoy RK, Storniolo AM, Tarassoff P, Nelson R, Dorr FA, Stephens CD and Von Hoff DD: Improvements in survival and clinical benefit with gemcitabine as first-line therapy for patients with advanced pancreas cancer: a randomized trial. J Clin Oncol 15: 2403-2413, 1997.

3 Conroy T, Desseigne F, Ychou M, Bouché O, Guimbaud R, Bécouarn Y, Adenis A, Raoul JL, Gourgou S, de la Fouchardiere C, Bennouna J, Bachet JB, Khemissa F, Péré-Vergé D, Delbaldo C, Assenat E, Chauffert B, Michel P, Montoto C and Ducreux M: FOLFIRINOX versus gemcitabine for metastatic pancreatic cancer. N Engl J Med 364: 1817-1825, 1997.

4 Gourgou-Bourgade S, Bascoul-Mollevi C, Desseigne F, Ychou M, Bouché O, Guimbaud R, Bécouarn Y, Adenis A, Raoul JL, Boige $\mathrm{V}$, Bérille $\mathrm{J}$ and Conroy T: Impact of FOLFIRINOX compared with gemcitabine on quality of life in patients with metastatic pancreatic cancer: results from the PRODIGE 4/ACCORD 11 randomized trial. J Clin Oncol 31: 23-29, 2013.

5 Therasse P, Arbuck SG, Eisenhauer EA, Wanders J, Kaplan RS, Rubinstein L, Verweij J, Van Glabbeke M, Van Oosterom AT, Christian MC and Gwyther SG: New guidelines to evaluate the response to treatment in solid tumors. European Organization for Research and Treatment of Cancer, National Cancer Institute of the United States, National Cancer Institute of Canada. J Natl Cancer Inst 92: 205-216, 2000.

6 Weber A, Kehl V, Mittermeyer T, Herberich E, Röthling N, Schmid RM and Prinz C: Prognostic factors for survival in patients with unresectable pancreatic cancer. Pancreas 39: 12471253, 2010.

7 Park JK, Yoon YB, Kim Y-T, Ryu JK, Yoon WJ and Lee SH: Survival and prognostic factors of unresectable pancreatic cancer. J Clin Gastroenterol 42: 86-91, 2008.

8 Trigui B, Barrier A, Flahault A and Huguier M: Prognostic factors in advanced pancreatic cancer. Multivariate analysis of predictive survival score. University Surgery Association. Ann Chir 125: 625-630, 2000.

9 David M, Lepage C, Jouve J-L, Jooste V, Chauvenet M, Faivre $\mathrm{J}$ and Bouvier AM: Management and prognosis of pancreatic cancer over a 30-year period. Br J Cancer 101: 215-218, 2009.

10 Inal A, Kos FT, Algin E, Yildiz R, Berk V, Tugba Unek I, Colak D, Kucukoner $M$ and Tamer Elkiran E: Prognostic factors in patients with advanced pancreatic cancer treated with gemcitabine alone or gemcitabine plus cisplatin: retrospective analysis of a multicenter study. J BUON 17: 102105, 2012.

11 Mohelnikova-Duchonova B and Melichar B: Human equilibrative nucleoside transporter 1 (hENT1): do we really have a new predictive biomarker of chemotherapy outcome in pancreatic cancer patients? Pancreatology 13: 558-563, 2013.

12 Spratlin J, Sangha R, Glubrecht D, Dabbagh L, Young JD, Dumontet C, Cass C, Lai R and Mackey J: The absence of human equilibrative nucleoside transporter 1 is associated with reduced survival in patients with gemcitabine-treated pancreas adenocarcinoma. Clin Cancer Res 10: 6956-6961, 2004.

13 Ben Q, An W, Wang L, Wang W, Yu L and Yuan Y: Validation of the Pretreatment Neutrophil-Lymphocyte Ratio as a Predictor of Overall Survival in a Cohort of Patients With Pancreatic Ductal Adenocarcinoma. Pancreas 44: 471-477, 2015.

14 Stotz M, Szkandera J, Stojakovic T, Seidel J, Samonigg H, Kornprat P, Schaberl R, Seggewies F, Hoefler G, Gerger A and Pichler M: The lymphocyte to monocyte ratio in peripheral blood represents a novel prognostic marker in patients with pancreatic cancer. Clin Chem Lab Med 53: 499-506, 2015.

15 Eto K, Kawakami H, Kuwatani M, Kudo T, Abe Y, Kawahata S, Takasawa A, Fukuoka M, Matsuno Y, Asaka M and Sakamoto $\mathrm{N}$ : Human equilibrative nucleoside transporter 1 and Notch 3 can predict gemcitabine effects in patients with unresectable pancreatic cancer. Br J Cancer 108: 1488-1494, 2013.

16 Jordheim LP and Dumontet C: Do hENT1 and RRM1 predict the clinical benefit of gemcitabine in pancreatic cancer? Biomark Med 7: 663-671, 2013.

17 Greenhalf W, Ghaneh P, Neoptolemos JP, Palmer DH, Cox TF, Lamb RF, Garner E, Campbell F, Mackey J and Costello E: Pancreatic Cancer hENT1 Expression and Survival From Gemcitabine in Patients From the ESPAC-3 Trial. J Natl Cancer Inst 106: djt347, 2013. 
18 Farrell JJ, Elsaleh H, Garcia M, Lai R, Ammar A, Regine WF, Abrams R, Benson A, Macdonald J, Cass C, Dicker A and Mackey J: Human equilibrative nucleoside transporter 1 levels predict response to gemcitabine in patients with pancreatic cancer. Gastroenterology 136: 187-195, 2009.

19. Svrcek M, Cros J, Maréchal R, Bachet JB, Fléjou JF and Demetter P: Human equilibrative nucleoside transporter 1 testing in pancreatic ductal adenocarcinoma: a comparison between murine and rabbit antibodies. Histopathology 66: 457-462, 2015.

20 Bachmann K, Neumann A, Hinsch A, Nentwich MF, El Gammal AT, Vashist Y, Perez D, Bockhorn M, Izbicki J and Mann O: Cyclin D1 is a strong prognostic factor for survival in pancreatic cancer: Analysis of CD G870A polymorphism, FISH and immunohistochemistry. J Surg Oncol 111: 316-323, 2014.

21 Pang E-J, Yang R, Fu X-B and Liu Y-F: Overexpression of long non-coding RNA MALAT1 is correlated with clinical progression and unfavorable prognosis in pancreatic cancer Tumour Biol 36: 2403-2407, 2015.
22 Von Hoff DD, Ervin T, Arena FP, Chiorean EG, Infante J, Moore M, Seay T, Tjulandin SA, Ma WW, Saleh MN, Harris M, Reni M, Dowden S, Laheru D, Bahary N, Ramanathan RK, Tabernero J, Hidalgo M, Goldstein D, Van Cutsem E, Wei X, Iglesias J and Renschler MF: Increased survival in pancreatic cancer with nabpaclitaxel plus gemcitabine. N Engl J Med 369: 1691-1703, 2013. 